\section{Role of neuron specific enolase as a biomarker in Parkinson's disease}

\author{
Rajib Dutta* \\ MD, Neurology, India
}

\section{Abstract}

Parkinson's disease (PD) is thought to be the most common neurodegenerative disease with movement disorder. The key motor symptoms are rigidity, tremor, akinesis/hypokinesia/ bradykinesia, and postural instability. However, in our day-to-day clinical practice we tend to see several other symptoms which may be motor or non-motor. Non-motor symptoms (NMS) are quite common and debilitating. The pathological hallmarks of PD are loss of dopaminergic neurons in the substantia nigra pars compacta (SNPc) and accumulation of unfolded or misfolded alphasynuclein. Diagnosis of PD is difficult in the pre-motor stage. Late diagnosis renders a substantial loss of dopaminergic neurons in SNPc and spread of disease in other parts of the brain. This may manifest as either full blown symptoms requiring multiple medications or may even lead to life threatening condition due to lack of early diagnostic tools and techniques. Biomarkers are required to diagnose PD at a very early stage when prevention is possible. Hence, we see a lot of interest among researchers involved in finding a biomarker specific to the disease. Biomarkers may be clinical, image based, genetic, and biochemical. Cerebrospinal fluid (CSF) and serum markers which may correlate with disease pathophysiology are of great significance. One such molecule which recently gained a lot of attention is neuron-specific enolase (NSE). The main aim of this paper is to highlight the role of NSE in predicting neurodegeneration and neuroinflammation ultimately reflecting damage of brain cells in PD.

\section{Introduction}

Parkinson's disease [PD] is a common progressive neurodegenerative movement disorder [1]. Most important pathological hallmark of PD is loss of dopaminergic neurons in SNPc and presence of Lewy bodies, which contains an abundant amount of $\alpha$-synuclein $[2,3]$.

Prevalence of PD is estimated to be around $0.3 \%$ in the general population, $1.0 \%$ in people over 60 years, and $3 \%$ in people older than 80 years in industrialized countries [4]. In European countries estimated prevalence ranges from 65 to 12,500 , whereas incidence rates range from 5 to 346 per 100,00 person years [5].

Age is considered to be a significant risk factor for PD [6]. However, risk of men in developing PD is 2 times higher than women, but women have faster progression and higher mortality rate in PD [7]. Pesticides and rural living had been linked to PD $[8,9]$. Beta2 receptors antagonist is linked to PD, whereas beta 2 agonist decreases the risk $[10,11]$.

Statins [12,13], cigarette smoking [8], drinking coffee [14,15], and calcium channel blockers [16] have inverse association in PD. Hyperuricemia or gout [17-20], and use

\section{More Information}

*Address for Correspondence: Rajib Dutta, MD, Neurology, India,

Email: rajibdutta808@gmail.com

Submitted: June 23, 2021

Approved: July 05, 2021

Published: July 06, 2021

How to cite this article: Dutta R. Role of neuron specific enolase as a biomarker in Parkinson's disease. J Neurosci Neurol Disord. 2021; 5 : 061-068.

DOI: 10.29328/journal.jnnd.1001052

ORCiD: orcid.org/0000-0002-6129-1038

Copyright: (c) 2021 Dutta R. This is an open access article distributed under the Creative Commons Attribution License, which permits unrestricted use, distribution, and reproduction in any medium, provided the original work is properly cited.

Keywords: Cerebrospinal fluid; CSF; Serum; Neuron specific enolase; NSE; Parkinson's disease

Abbreviations: PD: Parkinson's Disease; NMS: Non-Motor Symptoms; SNPc: Substantia Nigra Pars Compacta; CSF: Cerebrospinal Fluid; NSE: Neuron-Specific Enolase; NSAIDs: Nonsteroidal Anti-Inflammatory Drugs; FDG-PET: Fluorodeoxyglucose-Positron Emission Tomography; SPECT: Single-Photon Emission Computed Tomography; MIBG: Metaiodobenzylguanidine; NfL: Neurofilament Light; MAPK: Mitogen-Activated Protein Kinases; PI3K: Phosphatidylinositol 3 Kinase; IFN: Interferon; IL: Interleukin; TNF: Tumor Necrosis Factor; NO: Nitric Oxide; mRNA: Messenger Ribonucleic Acid; TBI: Traumatic Brain Injury; AD: Alzheimer's Disease; MSA: Multiple System Atrophy; DLB: Dementia With Lewy Bodies; $\mathrm{H}-\mathrm{Y}$ : Hoehn and Yahr; UPDRS: Unified Parkinson's Disease Rating Scale; SCLC: Small-Cell Lung Cancer; NSCLC: Non-Small-Cell Lung Carcinoma; GABA: Gamma Aminobutyric Acid

Check for updates

OPEN ACCESS

of NSAIDS [21-24] have conflicting evidence. Positive family history is considered to be a risk factor for PD [25]. The relative risk in first-degree relatives of PD cases increases by $2-3$ folds if compared to controls [26,27]. $5 \%-15 \%$ of cases are linked to familial form of PD [28-30]. A handful of genes are linked to PD [28,29,31,32].

Diagnosis of PD is mainly clinical. The diagnostic criteria had been recently updated by movement disorder society (MDS) [33]. It consists of variety of motor and non-motor symptoms. Motor symptoms may include gait disturbances 
(freezing of gait, festination, obstacle hesitation) postural abnormalities (PISA syndrome and camptocormia), micrographia, hypomimia, and alterations in eye movements or blinking apart from four cardinal symptoms of tremor, rigidity, bradykinesia, and postural instability [34].

NMS comprises of psychiatric symptoms (apathy, depression, anxiety, hallucination, psychosis), hyposmia, cognitive impairment (mild cognitive impairment and dementia), sensory symptoms, dysphagia, sialorrhea, dysarthria, hypophonia, sleep-wake cycle disturbances, gastro intestinal symptoms (delayed/reduced stomach emptying, constipation), genitourinary symptoms (sexual dysfunction, decreased libido, urinary frequency and urgency) and cardiovascular symptoms (post-prandial and postural blood pressure variations, dysrhythmias) [35-37].

In spite of having a strict diagnostic-criteria of PD, there are several diseases or disorders which can mimic PD. These disorders may comprise of secondary parkinsonism, atypical parkinsonism, and other neurodegenerative diseases [38]. MRI imaging can aid in differential diagnosis, however nondiagnostic for PD per se [39]. Complex imaging like FDG-PET [40], SPECT [41], and MIBG scintigraphy [42,43] can aid in diagnosis of PD. However, the only issue is their availability in small centers and developing world.

Glial cells are known to produce toxic or trophic factors responsible for neuronal cell death or survival $[44,45]$. Glial cells may be responsible for pathophysiology of neuronal degeneration in PD [46,47]. Few studies have shown that when $50-70 \%$ of dopaminergic neurons are lost in SNPc, clinical symptoms of PD manifests [48-50]. Loss of dopaminergic neurons and significant glial reaction are seen in post mortem parkinsonian brains [51]. However, an interesting thing to note is that some neurons are vulnerable to this pathologic process compared to others. It is also reported that dopaminergic neurons easily degenerate in regions with less astrocytes [52-56].

Great interest is seen among research community to find a biomarker for PD which can differentiate PD patients from healthy controls. Until now, only CSF alpha-synuclein and neurofilament light (NfL) chains are considered to be specific for PD. Recently, few researches have focused on NSE and their quantification either in CSF or serum of neurodegenerative diseases [57-59].

\section{Neuron specific enolase and PD}

A glycolytic enzyme which catalyzes the conversion of 2-phosphoglycerate (2-PG) to phosphoenolpyruvate (PEP) is enolase. Enolase is known to exist in the form of several tissuespecific isoenzymes, consisting of hetero or homodimers of 3 different monomer-isoforms (alpha, beta, and gamma) $[60,61]$.
NSE also known as human enolase 2 (ENO2) is a $78 \mathrm{kDa}$ gamma-homodimer [62,63]. The NSE gene is located on chromosome 12. It consists of 11 coding exons and spans more than 9213 nucleotides [64]. The biological half-life (t1/2) of NSE in body fluids is approximately 24 hours [62].

It is the dominant enolase-isoenzyme found in neuronal and neuroendocrine tissues [62]. Its levels in other tissues are negligible, except lymphocyte, platelets, and erythrocytes [65]. However, glial cells and astrocytes are also shown to express both homo and heterodimeric forms of the enzyme [60]. $\gamma$-enolase is also known to be in cells of the amine precursor uptake and decarboxylation lineage $[63,64,66]$.

NSE is mainly cytosolic but membrane localization is also being reported based on the extracellular milieu and neurotrophicity $[62,66]$. In a normal state, NSE is not secreted by neuronal cells but only when damage occurs, it is secreted into the extracellular space $[62,64,67]$. A recent study had found a dual role of NSE, which may be protective or destructive in nature [68]. NSE is known to cause neuroinflammation, neurodegeneration, and even neuroprotection $[64,68]$.

The neurotrophic factor exhibited by NSE is based on two important pathways, MAPK and PI3K which helps in the translocation of enolase to plasma membrane of the cell $[63,64,68]$. NSE can promote neuroinflammation by activating microglial cells $[64,68]$. Translocation of enolase to plasma membrane has its downside too because it leads to production and release of proinflammatory cytokines like IFN- $\gamma$, IL- $1 \beta$, TNF- $\alpha$, NO, chemokines, and reactive oxygen species (ROS) $[62,68,69]$.

NSE is considered as a marker of neurodegeneration as alteration of level is linked to neuronal damage and loss $[64,68]$. Serum levels of NSE correlated with intracranial bleeding post traumatic brain injury [70,71]. NSE mRNA expression levels have been found to be reduced in postmortem cortical brain tissue in cases with PD [68].

NSE levels in serum and CSF are related to extent of neuronal damage in conditions like ischemic stroke [72-76], TBI [70,71,77], AD [78,79], and MSA [80]. A study by Schaf, et al. did not find any changes in serum levels of NSE in PD patients compared to controls [81].

A recent study by Katayama etal. looked at the CSF NSE of 78 patients which included 27 patients with PD/DLB, 34 patients with non-PD/DLB (other neurodegenerative disorders), and 17 controls. They found out CSF levels of NSE can be used to discriminate PD/DLB from non-PD/DLB because significantly elevated CSF NSE was detected in the non-PD/DLB group [82].

A recent case-control study from Poland looked at CSF NSE levels in 58 PD patients and in 28 healthy control subjects. They found out CSF NSE was significantly increased in PD patients compared to healthy controls. However, no significant correlation was found between CSF NSE levels and 
disease severity assessed either in H-Y scale or in UPDRS part III or duration. This shows CSF NSE is not a useful marker to detect progression of the disease.

The authors believe CSF NSE can be promising biomarker of the axonal and glial degeneration seen in PD patients. CSF NSE levels also provided a high discrimination value between PD and healthy controls, with $78.6 \%$ sensitivity and $74.1 \%$ specificity [83].

\section{Discussion}

Enolase is superabundant in cytosol and is a multifunctional enzymatic protein. It has can travel to the plasma membrane on receiving excitatory signals. Membrane expression of enolase is often seen on activated microglia, macrophages, and astrocytes. This can trigger inflammatory response with production of cytokines and chemokines and degradation of extracellular matrix. Thismaylead to migration ofinflammatory cells to the injury site and promote more inflammation. It can behave as a plasminogen receptor and cause damage to tissues when translocated to cell surface [62].

NSE is a cell specific isoenzyme of enolase, which is involved in glycolysis. Expression of NSE in cytoplasm of neurons, which occurs $\alpha \gamma$ - and $\gamma \gamma$-dimer happens late in neural differentiation. It is therefore considered to be a marker for neural maturation over time.

Human NSE is a major brain protein that constitutes between $0.4 \%$ and $2.2 \%$ of the total soluble protein of brain, depending on the region. In some neurons NSE accounts for $3 \%-4 \%$ of the total soluble protein [84]. It is specific for peripheral neuroendocrine cells and neurons.

Blood NSE is currently considered as a reliable tumor marker of SCLC as far as diagnosis, prognosis, and follow up is concerned [85,86]. Increased NSE is also reported in NSCLC $[87,88]$. NSE is also useful at diagnosis of NETs (neuroendocrine tumors) and gastroenteropancreatic (GEP)NETs $[89,90]$.

Blood levels of NSE is increased in all stages of neuroblastoma, and greater increase has been linked to metastatic disease [91]. It is also increased in malignant pheochromocytoma [92,93], Guillain-Barré syndrome [94], Creutzfeldt-Jakob disease [95-97], carcinoid tumors [98], dysgerminomas [99,100], immature teratomas [101,102], Merkel cell tumor [103], melanoma [104], seminoma [105], renal cell carcinoma [106].

Among neurological diseases, increased NSE is associated with intracerebral hemorrhage [70,71], ischemic stroke [72-76], seizures [107,108], TBI [70,71,77], and comatose patients after cardiopulmonary resuscitation for cardiac arrest [109-113], newborns with perinatal hypoxic-ischemic encephalopathy [114-116], acute spinal cord injury [62,117119].
It is very evident that serum NSE is studied very less in PD patients and other neurological diseases mentioned above. We need a specific biomarker to diagnosis PD because of the presence of atypical parkinsonism or secondary parkinsonism which can behave the same way as PD in the very early stage when only $10-20 \%$ of dopaminergic neurons are lost in SNPc.

Current markers we have now are either not available worldwide or not cost-effective. It is of utmost importance at this juncture to look for blood or CSF biomarker to confirm the diagnosis of PD at an early stage when prevention might be possible along with prognostication, predictability of individual treatment response, and monitoring of disease progression.

PD is associated with cognitive dysfunction. Two known subtypes are mild cognitive impairment and Parkinson's disease dementia (PDD) [120]. The anatomical changes may be seen in several brain parts in PD patients with impairment in cognition. These changes might be seen in a) cerebellum; b) basal ganglia; c) limbic system; d) thalamus; e) hypothalamus; f) glial cells; g) locus coeruleus [121].

Mixed pathology and several underlying pathogenic processes are responsible for uncertainty and underdiagnosis of PD patients [122]. On one hand we have the Braak staging which consists of stage $1-6$, where stage 1 being the starting of the spread and deposition of a-synuclein in the lower brainstem and the olfactory system, whereas stage 6 is the neocortical invasion of motor and sensory areas in brain [123-125]. On the other hand, we have an emerging role of striatal neurotransmitters in the pathophysiology in PD. The related abnormalities include, decrease in dopamine, GABA, adenosine and increase in glutamate and acetylcholine [126].

A few scientific papers had also reported the similarity of pathological process in brain of AD and PDD. About 40\%-50\% of PDD patients may satisfy AD diagnostic criteria $[127,128]$. Several pathological processes in different stages of disease may be the reason behind absence of a single biomarker specific to $\mathrm{PD}$.

\section{Conclusion}

PD is a common neurodegenerative disease where symptoms appear late. It can be divided into prodromal, preclinical, and clinical. Till date, we don't have a single specific and sensitive biomarker to diagnose PD in preclinical stage. About $60 \%$ of dopaminergic neurons are already lost in SNPc when clinical symptoms become evident in PD individuals. Specific and sensitive biomarkers are needed to diagnose the disease early. These new biomarkers can be a game changer in diagnosis, identifying individual at-risk of PD, prognosis, individualized therapeutic response, and progression. Researchers should work meticulously in this field with a larger group of PD subjects, in different geographical locations, and in different disease stages to find a single brain derived protein, which will be able to differentiate PD from healthy subjects. 


\section{Disclosure}

The author has no relevant affiliations or financial involvement with any organization or entity with a financial interest in or financial conflict with the subject matter or materials discussed in the manuscript.

\section{Acknowledgment}

Thanks to my mentor Prof. Hui Fang Shang for constant support and Dr Swati for PubMed literature screening.

\section{References}

1. DeMaagd G, Philip A. Parkinson's Disease and Its Management: Part 1: Disease Entity, Risk Factors, Pathophysiology, Clinical Presentation, and Diagnosis. P T. 2015; 4: 504-532.

PubMed: https://pubmed.ncbi.nlm.nih.gov/26236139/

2. Stefanis L. a-Synuclein in Parkinson's disease. Cold Spring Harb Perspect Med. 2012; 2: a009399.

PubMed: https://pubmed.ncbi.nlm.nih.gov/22355802/

3. $\mathrm{Xu} \mathrm{L,} \mathrm{Pu} \mathrm{J.} \mathrm{Alpha-Synuclein} \mathrm{in} \mathrm{Parkinson's} \mathrm{Disease:} \mathrm{From}$ Pathogenetic Dysfunction to Potential Clinical Application. Parkinsons Dis. 2016; 2016: 1720621.

PubMed: https://pubmed.ncbi.nlm.nih.gov/27610264/

4. Lee A, Gilbert RM. Epidemiology of Parkinson Disease. Neurol Clin. 2016; 34: 955-965.

PubMed: https://pubmed.ncbi.nlm.nih.gov/27720003/

5. von Campenhausen S, Bornschein B, Wick R, et al. Prevalence and incidence of Parkinson's disease in Europe. EurNeuropsychopharmacol. 2005; 15: 473-490.

PubMed: https://pubmed.ncbi.nlm.nih.gov/15963700/

6. Reeve A, Simcox E, Turnbull D. Ageing and Parkinson's disease: why is advancing age the biggest risk factor?. Ageing Res Rev. 2014; 14: 19-30. PubMed: https://pubmed.ncbi.nlm.nih.gov/24503004/

7. Cerri S, Mus L, Blandini F. Parkinson's Disease in Women and Men: What's the Difference? J Parkinsons Dis. 2019; 9: 501-515.

PubMed: https://pubmed.ncbi.nlm.nih.gov/31282427/

8. Breckenridge CB, Berry C, Chang ET, Sielken RL Jr, Mandel JS. Association between Parkinson's Disease and Cigarette Smoking, Rural Living, Well-Water Consumption, Farming and Pesticide Use: Systematic Review and Meta-Analysis. PLoS One. 2016; 11: e0151841. PubMed: https://pubmed.ncbi.nlm.nih.gov/27055126/

9. Ball N, Teo WP, Chandra S, Chapman J. Parkinson's Disease and the Environment. Front Neurol. 2019; 10: 218.

10. Gronich N, Abernethy DR, Auriel E, Lavi I, Rennert G, Saliba W. $\beta 2$-adrenoceptor agonists and antagonists and risk of Parkinson's disease. Mov Disord. 2018; 33: 1465-1471.

PubMed: https://pubmed.ncbi.nlm.nih.gov/30941085/

11. Mittal S, Bjørnevik K, Im DS, Flierl A, Dong X, et al. $\beta 2$-Adrenoreceptor is a regulator of the $\alpha$-synuclein gene driving risk of Parkinson's disease. Science. 2017; 357: 891-898

PubMed: https://pubmed.ncbi.nlm.nih.gov/28860381/

12. Bai $S$, Song $Y$, Huang $X$, Peng $L$, Jia J, et al. Statin Use and the Risk of Parkinson's Disease: An Updated Meta-Analysis. PLoS One. 2016; 11: e0152564

PubMed: https://pubmed.ncbi.nlm.nih.gov/27019096/

13. Yan J, Qiao L, Tian J, et al. Liu A, Wu J, et al. Effect of statins on Parkinson's disease: A systematic review and meta-analysis. Medicine (Baltimore). 2019; 98: e14852.

PubMed: https://pubmed.ncbi.nlm.nih.gov/30896628/

14. Palacios N, Gao X, McCullough ML, Schwarzschild MA, Shah R, et al
Caffeine and risk of Parkinson's disease in a large cohort of men and women. Mov Disord. 2012; 27: 1276-1282.

PubMed: https://pubmed.ncbi.nlm.nih.gov/22927157/

15. Hong CT, Chan L, Bai $\mathrm{CH}$. The Effect of Caffeine on the Risk and Progression of Parkinson's Disease: A Meta-Analysis. Nutrients. 2020; 12: 1860.

PubMed: https://pubmed.ncbi.nlm.nih.gov/32580456/

16. Gudala K, Kanukula R, Bansal D. Reduced Risk of Parkinson's Disease in Users of Calcium Channel Blockers: A Meta-Analysis. Int J Chronic Dis. 2015; 2015: 697404.

PubMed: https://pubmed.ncbi.nlm.nih.gov/26464872/

17. Alonso A, Rodríguez LA, Logroscino G, Hernán MA. Gout and risk of Parkinson disease: a prospectivestudy. Neurology. 2007;69:1696-1700. PubMed: https://pubmed.ncbi.nlm.nih.gov/17954784/

18. Ungprasert P, Srivali N, Thongprayoon C. Gout is not associated with a lower risk of Parkinson's disease: A systematic review and metaanalysis. Parkinsonism Relat Disord. 2015; 21: 1238-1242. PubMed: https://pubmed.ncbi.nlm.nih.gov/26330027/

19. Singh JA, Cleveland JD. Gout and the risk of Parkinson's disease in older adults: a study of U.S. Medicare data. BMC Neurol. 2019; 19: 4. PubMed: https://pubmed.ncbi.nlm.nih.gov/30611222/

20. De Vera M, Rahman MM, Rankin J, Kopec J, Gao X, et al. Gout and the risk of Parkinson's disease: a cohort study. Arthritis Rheum. 2008; 59: 1549-1554.

PubMed: https://pubmed.ncbi.nlm.nih.gov/18975349/

21. Becker C, Jick SS, Meier CR. NSAID use and risk of Parkinson disease: a population-based case-control study. Eur J Neurol. 2011; 18: 1336-1342.

PubMed: https://pubmed.ncbi.nlm.nih.gov/21457177/

22. Gagne JJ, Power MC. Anti-inflammatory drugs and risk of Parkinson disease: a meta-analysis. Neurology. 2010; 74: 995-1002. PubMed: https://pubmed.ncbi.nlm.nih.gov/20308684/

23. Ren L, Yi J, Yang J, Li P, Cheng X, Mao P. Nonsteroidal antiinflammatory drugs use and risk of Parkinson disease: A doseresponse meta-analysis. Medicine (Baltimore). 2018; 97: e12172. PubMed: https://www.ncbi.nlm.nih.gov/pmc/articles/PMC6155958/

24. Poly TN, Islam MMR, Yang HC, Li YJ. Non-steroidal anti-inflammatory drugs and risk of Parkinson's disease in the elderly population: a metaanalysis. Eur J Clin Pharmacol. 2019; 75: 99-108. PubMed: https://pubmed.ncbi.nlm.nih.gov/30280208/

25. Torti M, Fossati C, Casali M, De Pandis MF, Grassini P, et al. Effect of family history, occupation and diet on the risk of Parkinson disease: A case-control study. PLoS One. 2020; 15: e0243612. PubMed: https://pubmed.ncbi.nlm.nih.gov/33332388/

26. Shino MY, McGuire V, Van Den Eeden SK, et al. Familial aggregation of Parkinson's disease in a multiethnic community-based case-control study. Mov Disord. 2010; 25: 2587-2594.

PubMed: https://www.ncbi.nlm.nih.gov/pmc/articles/PMC2978761/

27. Liu FC, Lin HT, Kuo CF, Hsieh MY, See LC, et al. Familial aggregation of Parkinson's disease and coaggregation with neuropsychiatric diseases: a population-based cohort study. Clin Epidemiol. 2018; 10 : 631-641.

PubMed: https://pubmed.ncbi.nlm.nih.gov/29881310/

28. Klein C, Westenberger A. Genetics of Parkinson's disease. Cold Spring Harb Perspect Med. 2012; 2: a008888. PubMed: https://pubmed.ncbi.nlm.nih.gov/22315721/

29. Pankratz N, Foroud T. Genetics of Parkinson disease. Genet Med. 2007; 9: 801-811

PubMed: https://pubmed.ncbi.nlm.nih.gov/18091429/

30. Karimi-Moghadam A, Charsouei S, Bell B, Jabalameli MR. Parkinson Disease from Mendelian Forms to Genetic Susceptibility: New Molecular Insights into the Neurodegeneration Process. Cell Mol 
Neurobiol. 2018; 38: 1153-1178.

PubMed: https://www.ncbi.nlm.nih.gov/pmc/articles/PMC6061130/

31. Cornelis Blauwendraat, Mike A Nalls, Andrew B Singleton. The genetic architecture of Parkinson's disease. 2020; 19: 170-178

PubMed: https://pubmed.ncbi.nlm.nih.gov/31521533/

32. Bandres-Ciga S, Diez-Fairen M, Kim JJ, Singleton AB. Genetics of Parkinson's disease: An introspection of its journey towards precision medicine. Neurobiol Dis. 2020; 137: 104782.

PubMed: https://pubmed.ncbi.nIm.nih.gov/31991247/

33. Postuma RB, Berg D, Stern M, Poewe W, Olanow CW, et al. MDS clinical diagnostic criteria for Parkinson's disease. Mov Disord. 2015 30: 1591-1601.

PubMed: https://pubmed.ncbi.nlm.nih.gov/26474316/

34. Moustafa AA, Chakravarthy S, Phillips JR, Gupta A, Keri S, et al. Motor symptoms in Parkinson's disease: A unified framework. Neurosci Biobehav Rev. 2016; 68: 727-740.

PubMed: https://pubmed.ncbi.nlm.nih.gov/27422450/

35. Pfeiffer RF. Non-motor symptoms in Parkinson's disease. Parkinsonism Relat Disord. 2016; 22 Suppl 1: S119-S122.

PubMed: https://pubmed.ncbi.nlm.nih.gov/26372623/

36. Poewe W. Non-motor symptoms in Parkinson's disease. Eur J Neurol. 2008; 15 Suppl 1: 14-20.

PubMed: https://pubmed.ncbi.nlm.nih.gov/18353132/

37. Pappala K, Garuda BR, Seepana G, Thalabaktula SK, Uppaturi AK Non-motor symptoms of Parkinson's disease: its prevalence across various stages and its correlation with the severity of the disease and quality of life. Ann Mov Disord 2019; 2: 102-8

38. Caproni S, Colosimo C. Diagnosis and Differential Diagnosis of Parkinson Disease. Clin Geriatr Med. 2020; 36: 13-24.

PubMed: https://pubmed.ncbi.nlm.nih.gov/31733693/

39. Heim B, Krismer F, De Marzi R, Seppi K. Magnetic resonance imaging for the diagnosis of Parkinson's disease. J Neural Transm (Vienna). 2017; 124: 915-964.

PubMed: https://pubmed.ncbi.nlm.nih.gov/28378231/

40. Walker Z, Gandolfo F, Orini S, et al. Clinical utility of FDG PET in Parkinson's disease and atypical parkinsonism associated with dementia. Eur J Nucl Med Mol Imaging. 2018; 45: 1534-1545. PubMed: https://pubmed.ncbi.nlm.nih.gov/29779045/

41. Wang L, Zhang $\mathrm{Q}$, Li H, Zhang $\mathrm{H}$. SPECT molecular imaging in Parkinson's disease. J Biomed Biotechnol. 2012; 2012: 412486. PubMed: https://pubmed.ncbi.nlm.nih.gov/22529704/

42. Nagayama $H$, Hamamoto $M$, Ueda $M$, Nagashima J, Katayama Y. Reliability of MIBG myocardial scintigraphy in the diagnosis of Parkinson's disease. J Neurol Neurosurg Psychiatry. 2005; 76: 249-251. PubMed: https://www.ncbi.nlm.nih.gov/pmc/articles/PMC1739515/

43. Sakakibara $R$, Tateno $F$, Kishi M, Tsuyusaki $Y$, Terada $H$, et al. MIBG myocardial scintigraphy in pre-motor Parkinson's disease: a review. Parkinsonism Relat Disord. 2014; 20: 267-273.

PubMed: https://pubmed.ncbi.nlm.nih.gov/24332912/

44. Jäkel S, Dimou L. Glial Cells and Their Function in the Adult Brain: A Journey through the History of Their Ablation. Front Cell Neurosci. 2017; 11: 24.

PubMed: https://pubmed.ncbi.nlm.nih.gov/28243193/

45. Giaume C, Kirchhoff F, Matute C, Reichenbach A, Verkhratsky A. Glia: the fulcrum of brain diseases. Cell Death Differ. 2007; 14: 1324-1335. PubMed: https://pubmed.ncbi.nlm.nih.gov/17431421/

46. Tremblay ME, Cookson MR, Civiero L. Glial phagocytic clearance in Parkinson's disease. Mol Neurodegener. 2019; 14: 16.

47. Kam TI, Hinkle JT, Dawson TM, Dawson VL. Microglia and astrocyte dysfunction in parkinson's disease. Neurobiol Dis. 2020; 144: 105028. PubMed: https://pubmed.ncbi.nlm.nih.gov/32736085/

48. Ross GW, Petrovitch H, Abbott RD, Nelson J, Markesbery W, et al.
Parkinsonian signs and substantia nigra neuron density in decendents elders without PD. Ann Neurol. 2004; 56: 532-539.

PubMed: https://pubmed.ncbi.nlm.nih.gov/15389895/

49. Lang AE, Lozano AM. Parkinson's disease. First of two parts. N Engl J Med. 1998; 339: 1044-1053.

PubMed: https://pubmed.ncbi.nlm.nih.gov/9761807/

50. Dauer W, Przedborski S. Parkinson's disease: mechanisms and models. Neuron. 2003; 39: 889-909.

PubMed: https://pubmed.ncbi.nlm.nih.gov/12971891/

51. Hartmann A. Postmortem studies in Parkinson's disease. Dialogues Clin Neurosci. 2004; 6: 281-293.

PubMed: https://pubmed.ncbi.nlm.nih.gov/22033507/

52. Kuter K, Olech $Ł$, Głowacka U. Prolonged Dysfunction of Astrocytes and Activation of Microglia Accelerate Degeneration of Dopaminergic Neurons in the Rat Substantia Nigra and Block Compensation of Early Motor Dysfunction Induced by 6-OHDA. Mol Neurobiol. 2018; 55: 3049-3066.

PubMed: https://pubmed.ncbi.nlm.nih.gov/28466266/

53. Rappold PM, Tieu K. Astrocytes and therapeutics for Parkinson's disease. Neurotherapeutics. 2010; 7: 413-423.

PubMed: https://pubmed.ncbi.nlm.nih.gov/20880505/

54. Miyazaki I, Asanuma M. Neuron-Astrocyte Interactions in Parkinson's Disease. Cells. 2020; 9: 2623.

PubMed: https://pubmed.ncbi.nlm.nih.gov/33297340/

55. Morales I, Sanchez A, Rodriguez-Sabate C, Rodriguez M. Striatal astrocytes engulf dopaminergic debris in Parkinson's disease: A study in an animal model. PLoS One. 2017; 12: e0185989. PubMed: https://pubmed.ncbi.nIm.nih.gov/29028815/

56. Sonninen TM, Hämäläinen RH, Koskuvi M, Oksanen M, Shakirzyanova A, et al. Metabolic alterations in Parkinson's disease astrocytes. Sci Rep. 2020; 10: 14474

PubMed: https://pubmed.ncbi.nlm.nih.gov/32879386/

57. Katayama T, Sawada J, Takahashi K, Yahara O. Cerebrospinal Fluid Biomarkers in Parkinson's Disease: A Critical Overview of the Literature and Meta-Analyses. Brain Sci. 2020; 10: 466. PubMed: https://pubmed.ncbi.nlm.nih.gov/32698474/

58. Papuć E, Rejdak K. Increased CSF NFL in Non-demented Parkinson's Disease Subjects Reflects Early White Matter Damage. Front Aging Neurosci. 2020; 12: 128.

PubMed: https://pubmed.ncbi.nlm.nih.gov/32477099/

59. Bäckström D, Linder J, Jakobson Mo S, Riklund K, Zetterberg $\mathrm{H}$, et al. $\mathrm{NfL}$ as a biomarker for neurodegeneration and survival in Parkinson disease. Neurology. 2020; 95: e827-e838.

PubMed: https://pubmed.ncbi.nlm.nih.gov/32680941/

60. Schmechel D, Marangos PJ, Zis AP, Brightman M, Goodwin FK. Brain endolases as specific markers of neuronal and glial cells. Science. 1978; 199: 313-315.

PubMed: https://pubmed.ncbi.nlm.nih.gov/339349/

61. Schmechel DE, Marangos PJ, Martin BM, Winfield S, Burkhart DS, et al. Localization of neuron-specific enolase (NSE) mRNA in human brain. Neurosci Lett. 1987; 76: 233-238.

PubMed: https://pubmed.ncbi.nlm.nih.gov/3587757/

62. Haque A, Ray SK, Cox A, Banik NL. Neuron specific enolase: a promising therapeutic target in acute spinal cord injury. Metab Brain Dis. 2016; 31: 487-495.

PubMed: https://pubmed.ncbi.nlm.nih.gov/26847611/

63. Vizin T, Kos J. Gamma-enolase: a well-known tumour marker, with a less-known role in cancer. Radiol Oncol. 2015; 49: 217-226. PubMed: https://pubmed.ncbi.nlm.nih.gov/26401126/

64. Dichev V, Kazakova M, Sarafian V. YKL-40 and neuron-specific enolase in neurodegeneration and neuroinflammation. Rev Neurosci. 2020; 31: 539-553.

PubMed: https://pubmed.ncbi.nlm.nih.gov/32045356/ 
65. Massabki PS, Silva NP, Lourenço DM, Andrade LE. Neuron specific enolase concentration is increased in serum and decreased in platelets of patientswithactivesystemicsclerosis. JRheumatol.2003;30:2606-2612. PubMed: https://pubmed.ncbi.nlm.nih.gov/14719201/

66. Xu CM, Luo YL, Li S, L ZX, Jiang L, et al. Multifunctional neuron-specific enolase: its role in lung diseases. Biosci Rep. 2019; 39: BSR20192732. PubMed: https://pubmed.ncbi.nlm.nih.gov/31642468/

67. Kawata K, Liu CY, Merkel SF, Ramirez SH, Tierney RT, Langford D. Blood biomarkers for brain injury: What are we measuring? Neurosci Biobehav Rev. 2016; 68: 460-473.

PubMed: https://pubmed.ncbi.nlm.nih.gov/27181909/

68. Haque A, Polcyn R, Matzelle D, Banik NL. New Insights into the Role of Neuron-Specific Enolase in Neuro-Inflammation, Neurodegeneration, and Neuroprotection. Brain Sci. 2018; 8: 33.

PubMed: https://pubmed.ncbi.nlm.nih.gov/29463007/

69. Polcyn R, Capone M, Hossain A, Matzelle D, Banik NL, et al. Neuron specific enolase is a potential target for regulating neuronal cell survival and death: implications in neurodegeneration and regeneration. Neuroimmunol Neuroinflamm. 2017; 4: 254-257.

PubMed: https://pubmed.ncbi.nlm.nih.gov/29423430/

70. Cheng F, Yuan Q, Yang J, Wang W, Liu H. The prognostic value of serum neuron-specific enolase in traumatic brain injury: systematic review and meta-analysis. PLoS One. 2014; 9: e106680.

PubMed: https://pubmed.ncbi.nlm.nih.gov/25188406/

71. Thelin EP, Jeppsson E, Frostell A, Svensson M, Mondello S, et al Utility of neuron-specific enolase in traumatic brain injury; relations to S100B levels, outcome, and extracranial injury severity. Crit Care. 2016; 20: 285

PubMed: https://pubmed.ncbi.nlm.nih.gov/27604350/

72. Missler U, Wiesmann M, Friedrich C, Kaps M. S-100 protein and neuron-specific enolase concentrations in blood as indicators of infarction volume and prognosis in acute ischemic stroke. Stroke. 1997; 28: 1956-1960.

PubMed: https://pubmed.ncbi.nlm.nih.gov/9341703/

73. Pandey A, Saxena K, Verma M, Bharosay A. Correlative study between neuron-specific enolase and blood sugar level in ischemic stroke patients. J Neurosci Rural Pract. 2011; 2: 50-54.

PubMed: https://pubmed.ncbi.nlm.nih.gov/21716874/

74. Oh S, Lee J, Na S, Park J, Choi Y, et al. Prediction of Early Clinical Severity and Extent of Neuronal Damage in Anterior-Circulation Infarction Using the Initial Serum Neuron-Specific Enolase Level. Arch Neurol. 2003; 60: 37-41.

PubMed: https://pubmed.ncbi.nlm.nih.gov/12533086/

75. Zaheer S, Beg M, Rizvi I, Islam N, Ullah E, et al. Correlation between serum neuron specific enolase and functional neurological outcome in patients of acute ischemic stroke. Ann Indian Acad Neurol. 2013; 16: 504-508.

PubMed: https://pubmed.ncbi.nlm.nih.gov/24339568/

76. Shash, M.H., Abdelrazek, R., Abdelgeleel, N.M. et al. Validity of neuron-specific enolase as a prognostic tool in acute ischemic stroke in adults at Suez Canal University Hospital. Egypt J Neurol Psychiatry Neurosurg. 2021; 57: 30.

77. El-Maraghi S, Heba $\mathrm{H}$, Hazema $\mathrm{H}$, Ahmed $\mathrm{Y}$, Hossam M. The prognostic value of neuron specific enolase in head injury. Egyptian $\mathrm{J}$ Crit Care Med. 2013: 1; 25-32.

78. Palumbo B, Siepi D, Sabalich I, Tranfaglia C, Parnetti L. Cerebrospinal fluid neuron-specific enolase: a further marker of Alzheimer's disease? Funct Neurol. 2008; 23: 93-96.

PubMed: https://pubmed.ncbi.nlm.nih.gov/18671910/

79. Schmidt FM, Mergl R, Stach B, Jahn I, Gertz HJ, et al. Elevated levels of cerebrospinal fluid neuron-specific enolase (NSE) in Alzheimer's disease. Neurosci Lett. 2014; 570: 81-85.

PubMed: https://pubmed.ncbi.nlm.nih.gov/24746933/
80. Abdo WF, De Jong D, Hendriks JC, Horstink MWIM, Kremer BPH, et al. Cerebrospinal fluid analysis differentiates multiple system atrophy from Parkinson's disease. Mov Disord. 2004; 19: 571-579. PubMed: https://pubmed.ncbi.nlm.nih.gov/15133823/

81. Schaf DV, Tort AB, Fricke D, Schestatsky P, Portela LVC, et al. S100B and NSE serum levels in patients with Parkinson's disease. Parkinsonism Relat Disord. 2005; 11: 39-43. PubMed: https://pubmed.ncbi.nlm.nih.gov/15619461/

82. Katayama T, Sawada J, Kikuchi-Takeguchi S, Kano K, Takahashi K, et al. Cerebrospinal fluid levels of alpha-synuclein, amyloid $\beta$, tau, phosphorylated tau, and neuron-specific enolase in patients with Parkinson's disease, dementia with Lewy bodies or other neurological disorders: Their relationships with cognition and nuclear medicine imaging findings. Neurosci Lett. 2020; 715: 134564.

PubMed: https://pubmed.ncbi.nlm.nih.gov/31733322/

83. Papuć E, Rejdak K. Increased Cerebrospinal Fluid S100B and NSE Reflect Neuronal and Glial Damage in Parkinson's Disease. Front Aging Neurosci. 2020; 12: 156.

PubMed: https://pubmed.ncbi.nlm.nih.gov/32792937/

84. Isgrò MA, Bottoni $P$, Scatena R. Neuron-Specific Enolase as a Biomarker: Biochemical and Clinical Aspects. Adv Exp Med Biol. 2015; 867: 125-143.

PubMed: https://pubmed.ncbi.nlm.nih.gov/26530364/

85. Liu L, Teng J, Zhang L, Cong P, Yao Y, et al. The Combination of the Tumor Markers Suggests the Histological Diagnosis of Lung Cancer. Biomed Res Int. 2017; 2017: 2013989.

PubMed: https://pubmed.ncbi.nlm.nih.gov/28607926/

86. Genet SAAM, Visser E, van den Borne BEEM, Youssef-El Soud M, Belderbos HNA, et al. Correction of the NSE concentration in hemolyzed serum samples improves its diagnostic accuracy in smallcell lung cancer. Oncotarget. 2020; 11: 2660-2668.

PubMed: https://pubmed.ncbi.nlm.nih.gov/32676167/

87. Ferrigno D, Buccheri G, Giordano C. Neuron-specific enolase is an effective tumour marker in non-small cell lung cancer (NSCLC). Lung Cancer. 2003; 41: 311-320.

PubMed: https://pubmed.ncbi.nlm.nih.gov/12928122/

88. Xu L, Lina W, Xuejun Y. The diagnostic value of serum CEA, NSE and MMP-9 for on-small cell lung cancer. Open Med (Wars). 2016; 11: 59-62. PubMed: https://pubmed.ncbi.nlm.nih.gov/28352768/

89. Sansone A, Lauretta R, Vottari S, Chiefari A, Barnabei A, et al. Specific and Non-Specific Biomarkers in Neuroendocrine Gastroenteropancreatic Tumors. Cancers (Basel). 2019; 11: 1113. PubMed: https://pubmed.ncbi.nlm.nih.gov/31382663/

90. Bocchini M, Nicolini F, Severi S, Bongiovanni A, Ibrahim T, et al Biomarkers for Pancreatic Neuroendocrine Neoplasms (PanNENs) Management-An Updated Review. Front Oncol. 2020; 10: 831. PubMed: https://pubmed.ncbi.nlm.nih.gov/32537434/

91. Georgantzi K, Sköldenberg EG, Stridsberg M, Kogner P, Jakobson A, et al. Chromogranin $A$ and neuron-specific enolase in neuroblastoma: Correlation to stage and prognostic factors. Pediatr Hematol Oncol. 2018; 35: 156-165.

PubMed: https://pubmed.ncbi.nlm.nih.gov/29737901/

92. Grouzmann E, Gicquel C, Plouin PF, Schlumberger M, Comoy E, et al. Neuropeptide $Y$ and neuron-specific enolase levels in benign and malignant pheochromocytomas. Cancer. 1990; 66: 1833-1835.

93. Liu S, Song A, Zhou X, Kong X, Li WA, et al. Malignant pheochromocytoma with multiple vertebral metastases causing acute incomplete paralysis during pregnancy: Literature review with one case report. Medicine (Baltimore). 2017; 96(44): e8535.

PubMed: https://pubmed.ncbi.nlm.nih.gov/29095319/

94. Mokuno K, Kiyosawa K, Sugimura K, Yasuda T, Riku S, et al. Prognostic value of cerebrospinal fluid neuron-specific enolase and S-100b protein in Guillain-Barré syndrome. Acta Neurol Scand. 1994; 89: 27-30. PubMed: https://pubmed.ncbi.nlm.nih.gov/8178624/ 
95. Vermuyten K. Determination of glial fibrillary acidic protein, S100 myelin basic protein and neuron specific enolase in cerebrospinal fluid from patients suffering from dementia. Acta Neurol Belg. 1989; 89: 318. PubMed: https://pubmed.ncbi.nlm.nih.gov/2483491/

96. Aksamit AJ Jr, Preissner CM, Homburger HA. Quantitation of 14-33 and neuron-specific enolase proteins in CSF in Creutzfeldt-Jakob disease. Neurology. 2001; 57: 728-730.

PubMed: https://pubmed.ncbi.nlm.nih.gov/11524493/

97. Kohira I, Tsuji T, Ishizu H, Takao Y, Wake A, et al. Elevation of neuron-specific enolase in serum and cerebrospinal fluid of early stage Creutzfeldt-Jakob disease. Acta Neurol Scand. 2000; 102: 385-387. PubMed: https://pubmed.ncbi.nlm.nih.gov/11125754/

98. Cunningham RT, Johnston CF, Irvine GB, Buchanan KD. Serum neurone-specific enolase levels in patients with neuroendocrine and carcinoid tumours. Clin Chim Acta. 1992; 212: 123-131.

PubMed: https://pubmed.ncbi.nlm.nih.gov/1477975/

99. Yoshida M, Koshiyama M, Konishi M, Fujii H, Nanno H, et al. Ovarian dysgerminoma showing high serum levels and positive immunostaining of placental alkaline phosphatase and neuron-specific enolase associated with elevation of serum prolactin level. Eur $\mathrm{J}$ Obstet Gynecol Reprod Biol. 1998; 81: 123-128.

PubMed: https://pubmed.ncbi.nlm.nih.gov/9846727/

100. Tatekawa Y, Kemmotsu H, Mouri T, Joe K, Ohkawa H. A case of pediatric ovarian dysgerminoma associated with high serum levels and positive immunohistochemical staining of neuron-specific enolase. J Pediatr Surg. 2004; 39: 1437-1439.

PubMed: https://pubmed.ncbi.nlm.nih.gov/15359410/

101. Kawata M, Sekiya S, Hatakeyama R, Takamizawa H. Neuron-specific enolase as a serum marker for immature teratoma and dysgerminoma. Gynecol Oncol. 1989; 32: 191-197.

PubMed: https://pubmed.ncbi.nlm.nih.gov/2910781/

102. Sato K, Fukuzawa T, Motoshi W, Sasaki H, Kudo H, et al. Rapidly growing immature retroperitoneal teratoma in a neonate. J Pediat Surg Case Rep. 2021; 69: 101891.

103. van Veenendaal LM, Bertolli E, Korse CM, Klop WMC, Tesselaar MET, van Akkooi ACJ. The Clinical Utility of Neuron-Specific Enolase (NSE) Serum Levels as a Biomarker for Merkel Cell Carcinoma (MCC). Ann Surg Oncol. 2021; 28: 1019-1028.

PubMed: https://pubmed.ncbi.nlm.nih.gov/32529274/

104. Sato S, Kato J, Sawada M, Horimoto K, Okura M, et al. Usefulness of neuron-specific enolase as a serum marker of metastatic melanoma. J Dermatol. 2020; 47: 1141-1148.

PubMed: https://pubmed.ncbi.nlm.nih.gov/32734632/

105. Fosså SD, Klepp O, Paus E. Neuron-specific enolase--a serum tumour marker in seminoma? Br J Cancer. 1992; 65: 297-299. PubMed: https://www.ncbi.nlm.nih.gov/pmc/articles/PMC1977726/

106. Ronkainen $H$, Soini $Y$, Vaarala $M H$, Kauppila S, Hirvikoski $P$ Evaluation of neuroendocrine markers in renal cell carcinoma. Diagn Pathol. 2010; 5: 28.

PubMed: https://pubmed.ncbi.nlm.nih.gov/20462442/

107. Kunda S, LaFrance-Corey RG, Khadjevand F, Worrell GA, Howe CL. Systemic evidence of acute seizure-associated elevation in serum neuronal injury biomarker in patients with temporal lobe epilepsy. Acta Epileptologica.2019; 1: 20

108. Shaik AJ, Reddy K, Mohammed N, Tandra SR, Rukmini Mridula Kandadai, Baba Kss S. Neuron specific enolase as a marker of seizure related neuronal injury. Neurochem Int. 2019; 131: 104509. PubMed: https://pubmed.ncbi.nlm.nih.gov/31404559/

109. Daubin C, Quentin C, Allouche S, Etard O, Gaillard C, et al. Serum neuron-specific enolase as predictor of outcome in comatose cardiacarrest survivors: a prospective cohort study. BMC Cardiovasc Disord. 2011; $11: 48$.

PubMed: https://pubmed.ncbi.nlm.nih.gov/21824428/
110. Vondrakova D, Kruger A, Janotka M, Malek F, Dudkova V, et al. Association of neuron-specific enolase values with outcomes in cardiac arrest survivors is dependent on the time of sample collection. Crit Care. 2017; 21: 172.

PubMed: https://www.ncbi.nlm.nih.gov/pmc/articles/PMC5501942/

111. Reisinger J, Höllinger K, Lang W, Steiner C, Winter T, et al. Prediction of neurological outcome after cardiopulmonary resuscitation by serial determination of serum neuron-specific enolase. Eur Heart J. 2007; 28: 52-58.

PubMed: https://pubmed.ncbi.nlm.nih.gov/17060343/

112. Stammet $P$, Collignon O, Hassager C, Wise MP, Hovdenes J, et al Neuron-Specific Enolase as a Predictor of Death or Poor Neurological Outcome After Out-of-Hospital Cardiac Arrest and Targeted Temperature Management at $33^{\circ} \mathrm{C}$ and $36^{\circ} \mathrm{C}$. J Am Coll Cardiol. 2015; 65: 2104-2114.

PubMed: https://pubmed.ncbi.nlm.nih.gov/25975474/

113. Rech TH, Vieira SR, Nagel F, Brauner JS, Scalco R. Serum neuronspecific enolase as early predictor of outcome after in-hospital cardiac arrest: a cohort study. Crit Care. 2006; 10: R133.

PubMed: https://pubmed.ncbi.nlm.nih.gov/16978415/

114. León-Lozano MZ, Arnaez J, Valls A, et al. Cerebrospinal fluid levels of neuron-specific enolase predict the severity of brain damage in newborns with neonatal hypoxic-ischemic encephalopathy treated with hypothermia. PLoS One. 2020; 15: e0234082.

PubMed: https://pubmed.ncbi.nlm.nih.gov/32479533/

115. Kelen D, Andorka C, Szabó M, Alafuzoff A, Kaila K, Summanen M. Serum copeptin and neuron specific enolase are markers of neonatal distress and long-term neurodevelopmental outcome. PLoS One. 2017; 12: e0184593.

PubMed: https://pubmed.ncbi.nlm.nih.gov/28931055/

116. Douglas-Escobar M, Weiss MD. Biomarkers of hypoxic-ischemic encephalopathy in newborns. Front Neurol. 2012; 3: 144.

PubMed: https://pubmed.ncbi.nlm.nih.gov/23130015/

117. Loy DN, Sroufe AE, Pelt JL, Burke DA, Cao QL, et al. Serum biomarkers for experimental acute spinal cord injury: rapid elevation of neuronspecific enolase and S-100beta. Neurosurgery. 2005; 56: 391-397. PubMed: https://pubmed.ncbi.nlm.nih.gov/15670387/

118. Pouw M, Hosman A, van Middendorp J, Verbeek MM, Vos PE, et al. Biomarkers in spinal cord injury. Spinal Cord. 2009; 47: 519-525. PubMed: https://pubmed.ncbi.nlm.nih.gov/19153591/

119. Li M, Wen H, Yan Z, Ding T, Long L, et al. Temporal-spatial expression of ENOLASE after acute spinal cord injury in adult rats. Neurosci Res. 2014; 79: 76-82.

PubMed: https://pubmed.ncbi.nlm.nih.gov/24321872/

120. Fang C, Lv L, Mao S, Dong H, Liu B. Cognition Deficits in Parkinson's Disease: Mechanisms and Treatment. Parkinsons Dis. 2020; 2020: 2076942

PubMed: https://pubmed.ncbi.nlm.nih.gov/32269747/

121. Prakash KG, Bannur BM, Chavan MD, Saniya K, Sailesh KS, et al. Neuroanatomical changes in Parkinson's disease in relation to cognition: An update. J Adv Pharm Technol Res. 2016; 7: 123-126. PubMed: https://www.ncbi.nlm.nih.gov/pmc/articles/PMC5052937/

122. Halliday GM, Holton JL, Revesz T, Dickson DW. Neuropathology underlying clinical variability in patients with synucleinopathies. Acta Neuropathol. 2011; 122: 187-204.

PubMed: https://pubmed.ncbi.nlm.nih.gov/21720849/

123. Jellinger KA. Is Braak staging valid for all types of Parkinson's disease? J Neural Transm (Vienna). 2019; 126: 423-431.

PubMed: https://pubmed.ncbi.nlm.nih.gov/29943229/

124. Dickson DW, Uchikado $H$, Fujishiro $H$, Tsuboi $Y$. Evidence in favor of Braak staging of Parkinson's disease. Mov Disord. 2010; 25 Suppl 1: S78-S82.

PubMed: https://pubmed.ncbi.nlm.nih.gov/20187227/ 
125. Rietdijk CD, Perez-Pardo P, Garssen J, van Wezel RJ, Kraneveld AD Exploring Braak's Hypothesis of Parkinson's Disease. Front Neurol. 2017; 8: 37.

PubMed: https://pubmed.ncbi.nlm.nih.gov/28243222/

126. Jamwal S, Kumar P. Insight Into the Emerging Role of Striatal Neurotransmitters in the Pathophysiology of Parkinson's Disease and Huntington's Disease: A Review. Curr Neuropharmacol. 2019; 17: 165-175.

PubMed: https://pubmed.ncbi.nlm.nih.gov/29512464/
127. Sabbagh MN, Adler CH, Lahti TJ, Connor DJ, Vedders L, et al. Parkinson disease with dementia: comparing patients with and without Alzheimer pathology. Alzheimer Dis Assoc Disord. 2009; 23: 295-297. PubMed: https://pubmed.ncbi.nIm.nih.gov/19812474/

128. Irwin DJ, Lee VM, Trojanowski JQ. Parkinson's disease dementia: convergence of $\alpha$-synuclein, tau and amyloid- $\beta$ pathologies. Nat Rev Neurosci. 2013; 14: 626-636.

PubMed: https://pubmed.ncbi.nlm.nih.gov/23900411/ 